\title{
La temporada de Colombia en Francia 2017: un intercambio de cooperación jamás visto
}

\author{
Fabián Sanabria \\ Comisario General
}

Luego de una exitosa realización de la Temporada Francesa en nuestro país, habiendo definido una programación de más de 200 eventos en todas las áreas, el 23 de junio de 2017, con la presencia del presidente Juan Manuel Santos, se logró un magnífico desembarque de Colombia en Francia. Cinco eventos marcaron esa inauguración: Un foroeconómico en el Ministerio de Finanzas Francés, una presentación ante las representaciones diplomáticas de la UNESCO de las oportunidades del Proceso de Paz en Colombia, la recepción del Doctorado Honoris Causa por parte del Presidente Santos en la Universidad Panteón Sorbona, la inauguración de la Plaza García Márquez en el Séptimo distrito de París, y el concierto de la Orquesta Binacional en la Filarmónica de París -donde se interpretó música tradicional colombiana y francesa.

A partir de allí, la programación colombiana en Francia tuvo como principal objetivo presentar un "nuevo rostro de Colombia", dispuesta a construir una paz estable y duradera, con amplias oportunidades de inversión en sus regiones. El acento fue marcado con la riqueza de su patrimonio. Grandes exposiciones se llevaron a cabo con 220 piezas del Museo del Oro de Bogotá en el Castillo de los Duques de Bretaña en Nantes, dos obras maestras del arte barroco colonial en el Museo del Louvre, y una pieza precolombina del Parque Arqueológico de San Agustín Patrimonio de la Humanidad- se prestó al Museo del Quai Branly. En seguida, las actividades y proyectos resaltaron la excepcional biodiversidad de Colombia, a través de numerosos encuentros, entreloscualesvalela pena destacar las actividades desarrolladas en el Museo de Historia Natural y el Museo del Hombre de París. La mayor riqueza de nuestras producciones culturales se compartió tanto en las artes visuales como escénicas, donde cabe destacar las más de 20 residencias de artistas a lo largo y ancho del país galo. Del mismo modo, al menos diez grandes exposiciones de arte, entre las cuales figuraron artistas de primer orden como Beatriz González y Johanna Calle, al igual que un centenar de artistas que presentaron sus obras en museos como Los Abattoirs de Toulouse, e individual y colectivamente en otras exposiciones que resaltaron la efervescencia del arte contemporáneo colombiano, a través de importantes focus en los Encuentros Fotográficos de Arles, en la Bienal Cosmópolis del Centro Pompidou y en la FIAC. A nivel de las artes escénicas, la danza estuvo presente en variados escenarios franceses, particularmente en la Maison de la Danse de Lyon y en el Festival Don Quijote de París. En teatro, dos piezas le dieron la vuelta a Francia: Labio de Liebre, del grupo de teatro Petra, y La Despedida, de Mapa Teatro, las cuales inspirándose en el conflicto colombiano mostraron la riqueza de la dramaturgia de nuestro país. La creatividad musical no pudo faltar con la participación de diversos grupos colombianos en numerosos festivales, donde desde la música tradicional hasta los ritmos juveniles y digitales resonaron en Francia. Por último, la presencia de Colombia en los principales salones de negocios y de turismo, al igual que los sabores tradicionales $\mathrm{y}$ un buen número de coloquios académicos, que también se realizaron al compás de las presentaciones de los principales escritores traducidos al francés- y de una gran muestra de la cinematografía colombiana, sumaron un total de 207 proyectos aprobados, con cerca de más de 300 actividades realizadas que revistieron de gala nuestra Temporada.

La experiencia fue magnífica. Nunca antes Colombia había tenido un intercambio de cooperación con un país extranjero de 
esta naturaleza. Numerosos proyectos han redundando en acuerdos de cooperación, especialmente a nivel de inversión de Francia en Colombia y de intercambios universitarios. Para la financiación de todas nuestras actividades el Ministerio de Cultura hizo un gran esfuerzo. Se espera que en los próximos años se pueda plantear un proyecto de ley para constituir mecenazgos culturales que posibiliten un mejor entendimiento y cooperación entre los ámbitos de la economía y la cultura, los cuales no sólo son complementarios sino deben vislumbrarse como aliados estratégicos. Así, sector público y privado deben trabajar más de la mano en materia cultural. Gracias a la cultura, es decir, a las más robustas producciones creativas de nuestros modos de sentir, pensar y actuar es que podemos extender nuestros brazos a otras naciones e intercambiar de modo más eficaz con ellas. Esta experiencia debería derivar en tareas urgentes que Colombia puede realizar a nivel de la cooperación internacional y atrayendo más y mejor al empresariado.

Indudablemente los eventos de la
inauguración, al igual que las grandes

exposiciones de arte, ocuparon un renglón prioritario en el desarrollodenuestra Temporada. Sentimos una gran acogida en los diversos festivales franceses, tanto de música como de danza y de teatro. Las residencias artísticas, y las obras producidas en ellas, muestran claramente que esto debe continuarse en el futuro. Del mismo modo, es importante potenciar convenios con instituciones como la Maison de la Danse de Lyon, la Red de Bibliotecas de París, y no debemos perder de vista la participación de Colombia en los principales festivales que, estamos seguros, nos seguirán invitando a enriquecer su programación. A nivel del intercambio universitario, los convenios se han multiplicado, y es deber, tanto del Ministerio de Educación Nacional como de las universidades colombianas, velar por su implementación y eficaz desarrollo. Finalmente, Colombia debe seguir insistiendo, con su presencia en los diferentes salones franceses de economía, gastronomía y turismo, en lograr posicionar en el mercado francés y europeo sus productos, así como una cierta internacionalización de sus sabores. 